\title{
Investigation of Long Term Evapotranspiration by Using Hamon Equation Factor and NDVI Data in Forest Plantations Area
}

\author{
Edwina Zainal, Kojima Toshiharu \\ River Basin Research Center of Gifu University, Gifu, Japan
}

\begin{abstract}
It is necessary to carry out comprehensive evaluation on forest management for water conservation forest function through quantification of hydrological process. To do a direct measurement in each forest area has many obstacles, therefore need to develop an approximation method. This study investigated ways to identify appropriate long term evapotranspiration factor $\left(f_{e p}\right)$ based on their monthly and annually performances in the small forest watershed. Evapotranspiration factor $\left(f_{e p}\right)$ is estimated by ratio of the actual evapotranspiration $\left(e_{t}\right)$ over the potential evapotranspiration $\left(e_{p}\right)$. The $e_{t}$ is describing the total loss of water where calculated from an indirect estimation using the water balance of a watershed. The $e_{p}$ values have been estimated by the Hamon equation at monthly and annually temporal scale. Performance analysis estimated values using the hydrological data and meteorological data for 24 years (1984-2007) were made. On the other hand, Normalized Difference of Vegetation Index (NDVI) data derived from remote sensing were used to assess the historic of leaf area change patterns. The result revealed a positive relationship between evapotranspiration factor and NDVI $\left(f_{e p}=1.3975 \mathrm{NDVI}+0.4875, r^{2}=0.30\right)$. This study produces a useable monthly evapotranspiration factor for Hamon PET (Potential Evapotranspiration) during the growing season. Furthermore the simple linear regression model was developed to establish a relationship between NDVI and the evapotranspiration factor for forest catchment area.
\end{abstract}

Keywords: correction factor of potential evapotranspiration, long-term water balance of forest, remote sensing

\section{Introduction}

Forest management and conservation are promoted according to the "Forest and Forestry Basic Plan" based on the "Forest and Forestry Basic Law" as well as the "National Forest Plan", "Prefectural Forest Plans", and "Municipality Forest Plans" to improve multiple functional roles (MAFF, 2013). Forest plays important function in conserving global environment such as maintain biodiversity, absorption of $\mathrm{CO}_{2}$, soil and land corrosion prevention, water resource conservation, and so on (Biao, Wenhua, Gaodi, \& Yu, 2010; Makino, Goto, Inoue, Sueyoshi, Okabe, Hasegawa, \& Okochi, 2006; Watanabe, Konishi, Ishihara, \& Tezuka, 2011; Razafindrable, He, Inoue, Ezaki, \& Shaw, 2010; Yamane, 2003).

Acknowledgements: This work was supported by JSPS KAKENHI Grantin-Aid for Scientific Research (C) (25420519) and Japanese Alps Inter-University Cooperative Project (Jalps). We acknowledge the important data in experimental forest and the helpful support provided by Gifu Prefecture and Forestry Agency, MAFF. The evapotranspiration estimated by eddy-covariance method and meteorological data at TKC site were provided by Dr. Taku M. Saitoh and Dr. Ichiro Tamagawa, Gifu University.

Edwina Zainal, Ph.D., research assistant, River Basin Research Center of Gifu University, Environmental Hydrology, Gifu, Japan.

Kojima Toshiharu, Ph.D., associate professor, River Basin Research Center of Gifu University, Environmental Hydrology Gifu, Japan.

Correspondence concerning this article should be addressed to Edwina Zainal, 1-1 Yanagido, Gifu 501-1193, Japan. 
The water conservation of forests is also known as "green dam" in Japan that has been widely recognized as one of the most important forest functions. Water conservation function of forest is classified into a flooding mitigation function for reducing the peak discharge during floods, water resources storage function for maintaining the river flow when no rain or drought mitigation functions (Calder, 2007; Kojima, Zainal, Oike, Ohashi, \& Shinoda, 2013; Sawai, Takara, \& Kobayashi, 2013; Sach, Svihla, Cernohous, \& Kantor, 2014; Elkin, Giuggiola, Rigling, \& Bugmann, 2015). The water resource storage function not only maintains the river flow in the upstream area where the forest exists but also serves as a water source for the downstream area. Moreover, the flood control function affects not only in upstream, middle mountainous area but also reduces downstream flooding. Good forest management can provide better water conservation function, otherwise poor forest management may not only degrade upstream but also downstream environmental conditions (Creed, Sass, Buttle, \& Jones, 2011; Miura, Amacher, Hofer, Ayanz, Ernawati, \& Thackway, 2015). How to design the forest management as water resource and how to conserve them is an important issue that related to all the residents living in the basin. As a matter of fact, to evaluate the watershed function of each forest is a difficult problem. By considering forests as hydrological systems that have hydrological processes during specific time, consequently, a better understanding of hydrological processes for forest management area is also needed for evaluation of watershed function. In the previous study (Kojima, Zainal, Oike, Ohashi, \& Shinoda, 2013), forest management at study area has not been performed actively after the plantation activity. The forest growth and having dense canopies can consume more water by evapotranspiration. Therefore, this study demonstrates how to develop a simple model for estimating the evapotranspiration.

The impact of forest management (e.g., thinning and planting) changes on hydrological regime that suggest forest consumes more water by evapotranspiration with resulting in reduced streamflow (Zhang, Dawes, \& Walker, 2001; Sun, McNulty, Myers, \& Cohen, 2008; Zainal, Ohashi, Sakurai, Kojima, \& Shinoda, 2012). The water recharge function of forest reduces the amount of direct flow due to the canopy blocked precipitation and the evapotranspiration process. The impact of forest management in increasing evapotranspiration has not been sufficiently evaluated. Zhang, Dawes, and Walker (2001) developed a model to estimate mean annual evapotranspiration with over 250 catchments from around the world. However, in most cases cannot be proposed to forest in Japan (Komatsu, 2008). Egami, Hayashi, Kawabe, Honda, and Shimaji (1995) and Murakami, Tsuboyama, Shimizu, Fujieda, and Noguchi (1999) investigated evapotranspiration by the short time period during summer season and forest stand age using water balance and model based on Penman-Monteith equation. After all, the long-term hydrological database is one of the most important way to evaluate water conservation function (Sato, Kojiri, Michihiro, Suzuki, \& Nakakita, 2013; Ryu, Jang, Kim, Choi, Engel, Yang, \& Lim, 2016).

In spite of the fact that evapotranspiration processes are complex and difficult to measure, the estimation represented by indirect procedures through correlation with meteorological factors that called potential evapotranspiration (PET) has widely been used (Alkaeed, Flores, Jinno, \& Tsutsumi, 2006; Fisher, Whittaker, \& Malhi, 2011; Arakaki, Shimizu, Kobeya, Ikuzawa, \& Shimizu, 2014). Though many usable models with inputs of meteorological data, only a few are suited for used up. Furthermore, Sawano, Hotta, Tanaka, and Tsuboyama (2015) developed a simple model based on observations data and meteorological data for large-scale regions. However, it is not long-term investigation and its results are useful for large-scale region, that cannot easily be applied in small forest watershed. Moreover, the impact of forest management is highly dependent on scale (Chisholm, Muller-Landau, Rahman, Bebber, Bin, Bohlman, \& Zimmerman, 2013), time, 
also different geographies will have differences in hydrological behavior.

Particularly, some procedures used to predict evapotranspiration involve some type of PET and the combination methods to derive the actual evapotranspiration (AET) (Ishii, 1989; Rao, Sun, Ford, \& Vose, 2011; Westerhoff, 2015). When considering the availability and reliability of meteorological data thus, Oudin, Hervieu, Michel, and Loumagne (2005) and Jianbio, Ge, Steven, and Devendra (2005) proposed that formula based on the surface net radiation as Priestly-Taylor and temperature as Hamon equation with correction for the criteria of availability data and correlations with AET values. In spite of fact that solar radiation is available only from routine weather station and the net radiation data are unavailable in study area, in this study the potential evapotranspiration was estimated by Hamon equation with correction factor.

The correction factor for Hamon equation was proposed by Tsukamoto (1992) involving Japan's forest area. It is simple enough to provide the correction factor and is called as an evapotranspiration factor.

$$
e_{t}=f_{e p} \cdot e_{p}
$$

where: $e_{t}$ is $\mathrm{AET}, f_{e p}$ is evapotranspiration factor and $e_{p}$ is PET. In this study, the Hamon is considering for estimation $e_{p}$ and the water balance method is considered as $e_{t}$. On the occasion of determination of actual evapotranspiration from catchment water balance must follow some criteria, which assume negligible change in catchment water storage and use long term data (Ward \& Trimble, 2004; Brutsaert, 2005). The concept requires validation of PET method for over longer period. The evapotranspiration from eddy covariance method fitted well with the evapotranspiration from the water balance method in experimental watershed of Japan forest area (Shimizu, Miyabuchi, \& Ogawa, 2003; Kosugi, \& Katsuyama, 2007). In addition, the heat fluxes of eddy-covariance measurements over an evergreen coniferous forest on steep slopes with cool temperate and snow have a similar accuracy as other topography (Saitoh, Tamagawa, Muraoka \& Koizumi, 2011). In order to assess the validity of equation (1), this study compared with monthly of eddy covariance evapotranspiration by energy budget and "reference of Hamon factor" by Tsukamoto (1992) to represent the monthly correction factor for forest Hamon PET.

On the other hand, recent studies identified that evapotranspiration is closed related to normalize difference vegetation index (NDVI) (Suzuki \& Masuda, 2004; Wang, Li, Cribb, \& Sparrow, 2007; Senay, Leake, Nagler, Artan, Dickinson, Cordova, \& Glenn, 2011). Furthermore, a simple linear regression model is developed to establish a general relationship between a normalized difference vegetation index (NDVI) from satellite data and the crop coefficient calculated based on estimation of crop evapotranspiration (Johnson \& Trout, 2012; Kamble, Irmak, \& Hubbard, 2013). Using the same logic, the similarities between forest evapotranspiration factor and NDVI values will show a potential simple linear model for the evapotranspiration factor as a function of the vegetation index in forest study area.

The objectives of the study were to: (1) analyze water balance in the study site, (2) develop ways for estimating forest evapotranspiration factor by ratio of AET that derived from catchment water balances over the Hamon PET across a range of the long-term availability data, and (3) establish the relationship between the evapotranspiration factor and NDVI that can be modeled reasonably to provide an effective predictive tool for determining evapotranspiration rates in forest area that are lacking weather data. In this study, we also attempt to develop a method to assess the watershed function easily by using the long-term hydrological observation data and satellite data in small forest watersheds.

\section{Study Site}

The study site was made in Futatsumori experimental watershed, Fukuoka district of Nakatsugawa, 
southeast of Gifu Prefecture, which belongs to the Kiso River sytem Japan at $35^{\circ} 33^{\prime} \mathrm{N}, 137^{\circ} 24^{\prime} \mathrm{E}$ with elevation range from 440 to 1,223 $\mathrm{m}$ (Figure 1). The main catchment is the Gaman Stream lower catchment (GS, $3.2 \mathrm{~km}^{2}$ ) and sub-catchments are the Gaman Stream upper catchment $\left(\mathrm{GU}, 0.6 \mathrm{~km}^{2}\right.$ ), the Morigahora intermediate catchment (MR, $0.5 \mathrm{~km}^{2}$ ), respectively, where the gauging weir is installed. Tree species composition over the area is dominated by cypress $67.0 \%$, red pine $4.5 \%$, cedar $4.3 \%$, needle leaf forest $19.9 \%$ hardwood, and broadleaf forest $4.3 \%$. The mean annual precipitation is $2,284.7 \mathrm{~mm}$ and the main temperature is $11.8^{\circ} \mathrm{C}$. The temperature analysis of study site has shown weak trend $\left(+0.00540{ }^{\circ} \mathrm{C} /\right.$ year $)$ of changing rates of temperature over the last 24 years, details shown in climate trend of Futatsumori (Gifu Prefecture, 2004).

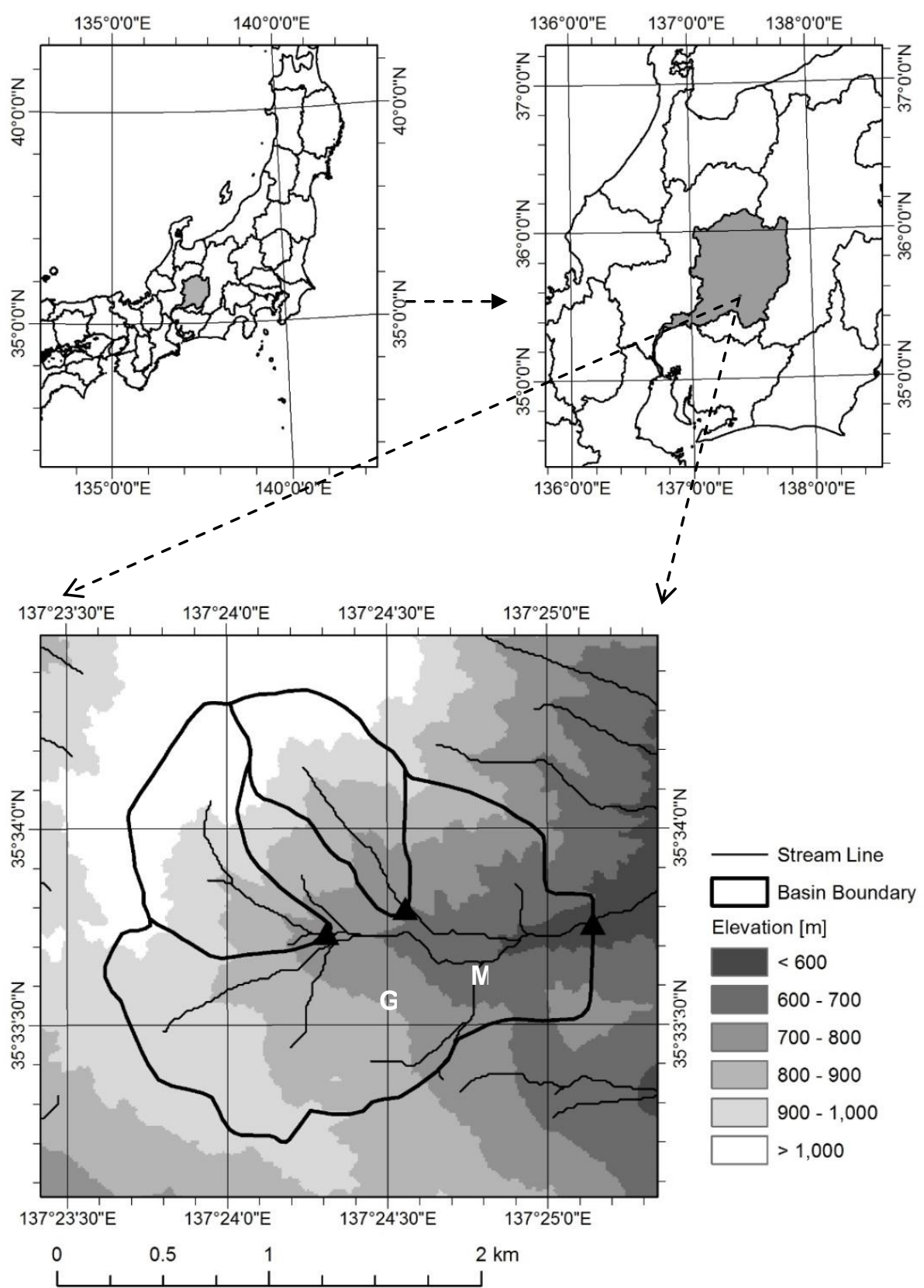

Figure 1. Location study area at Futatsumori, Nakatsugawa City of Gifu Prefecture, and Japan. 
This watershed is a model project for water and soil conservation in the five years period from fiscal year 1983 that have been carried out by by Gifu Prefecture Forestry Agency to achieve the effective use of water, soil conservation features, and forest resources. Moreover, forest management such as silvicultural thinning has been implemented from 1986 to 1988 in the study site. In addition, this region is upstream of Chukyo area (Nagoya and environs), many other dams have been installed and are using as an important water resource since a long time ago.

\section{Methods}

\section{Hamon PET}

Among various PET, Hamon expression is a method to calculate a simple monthly average PET by using mean monthly temperature and daylight hours which depend on latitude. It does not require fine weather observation, so it is possible to easily calculate the PET in all parts of the country. In Japan, the temperature and daylight sunshine as the input parameter is available from Automated Meteorological Data Acquisition System (AMeDAS). Hamon (1960) developed a simplified expression for PET that is represented by

$$
e_{p}=0.14 D_{0}^{2} P_{t}
$$

where, $e_{p}$ is the potential evapotranspiration in $\mathrm{mm} /$ day; $D_{0}$ is the possible hours of daily sunshine in units of 12 hours; $P_{t}$ is the saturated water vapor concentration at the mean temperature in $\mathrm{g} / \mathrm{m}^{3}$. The $P_{t}$ is expressed as

$$
P_{t}=216.7\left(e_{s} /(T+273.3)\right)
$$

where, $e_{s}$ is the saturated vapor pressure in $\mathrm{hPa}$ over water at temperature $(T)$ in ${ }^{\circ} \mathrm{C}$ was given by Tetens equation (1930) as

$$
e_{s}=6.1078 \times 10^{(17.27 T /(T+273.3))}
$$

\section{$E_{t}$ Estimation}

Over a land surface area, the actual evapotranspiration rate over a period of years can be expressed in terms of the water balance equation, which for the study purpose can be written as follows Brustsaert (2005) and Ward et al. (2004):

$$
e_{t}=P-Q
$$

where, $P$ is the precipitation in $\mathrm{mm} ; Q$ is the streamflow in $\mathrm{mm} ; e_{t}$ is AET. Here, it must be applied over sufficiently long period's data, so that water storage becomes less important. The water storage in the basin is not easily determined, an annual period is usually considered long enough to make water storage negligible. The long-term hydrological data (precipitation and runoff observation data) for the period of 1985 to 2007 have been measured in each catchment, but fewer data have not been recorded on 1995, 1996, and 1997 caused by instrument trouble. Monthly and annual $e_{t}$ was calculated from the years 1985 to 2007 as well as PET.

\section{Result and Discussion}

Validation of Monthly Evapotranspiration Factor $\left(f_{e p}\right)$

The $f_{e p}$ in the PET models is an empirical model that has been derived for many land surfaces for estimating either PET or AET. Jianbio, Ge, Steven, and Devendra (2005) and Zhou, Sun, Wang, Zhou, McNulty, Vose, and Amatya (2008) indicated different $f_{e p}$ for forest Hamon PET in different sites. In order to 
assess the validity of both methods and to evaluate the amplitude of seasonal fluctuations of evapotranspiration factor over the long term, likewise to provide a more accurate PET estimate, thus need to show the similarity of monthly evapotranspiration factor at each site. The comparison between areas at reference monthly Hamon factors (Tsukamoto, 1992), Hamon PET factor that is corrected based on eddy-covariance at Takayama site (Saitoh et al., 2011) and Hamon PET at study site that is corrected based on water balance have been shown on Table 1 and Figure 2.

The reference monthly Hamon factors was provided using the short-term water balance method at Kiryu site (Shiga Prefecture) and Higashiyama site (Aichi Prefecture). The $e_{t}$, at Takayama site (TKC site, $36^{\circ} 08^{\prime} \mathrm{N}$, $137^{\circ} 22^{\prime} \mathrm{E} ; 800 \mathrm{~m}$ a.s.1.), was obtained using the energy balance closure by eddy covariance method that was carried out from 2006 to 2008 . The average monthly $f_{e p}$ over three years on TKC site was calculated according to equation (1). At last, the average monthly $f_{e p}$ over 23 years on GS study site was calculated according to equation (1) while $e_{t}$ is estimated by equation (5).

Table 1

Monthly Evapotranspiration Factor for Hamon Forest PET $\left(f_{e p}\right)$

\begin{tabular}{lllll}
\hline Month & Aichi & Kiryu & TKC & GS \\
\hline 1 & 1.60 & 1.80 & 0.96 & 2.53 \\
2 & 1.40 & 1.48 & 1.42 & 1.90 \\
3 & 1.30 & 1.63 & 1.31 & 2.18 \\
4 & 1.10 & 1.12 & 1.31 & 0.85 \\
5 & 0.95 & 0.93 & 1.15 & 0.86 \\
6 & 0.80 & 0.75 & 0.95 & 1.01 \\
7 & 0.85 & 0.68 & 0.86 & 0.36 \\
8 & 1.05 & 0.80 & 0.93 & 0.78 \\
9 & 1.20 & 0.92 & 0.93 & 1.14 \\
10 & 1.50 & 1.48 & 1.03 & 1.23 \\
11 & 1.50 & 1.62 & 0.91 & 1.58 \\
\hline
\end{tabular}

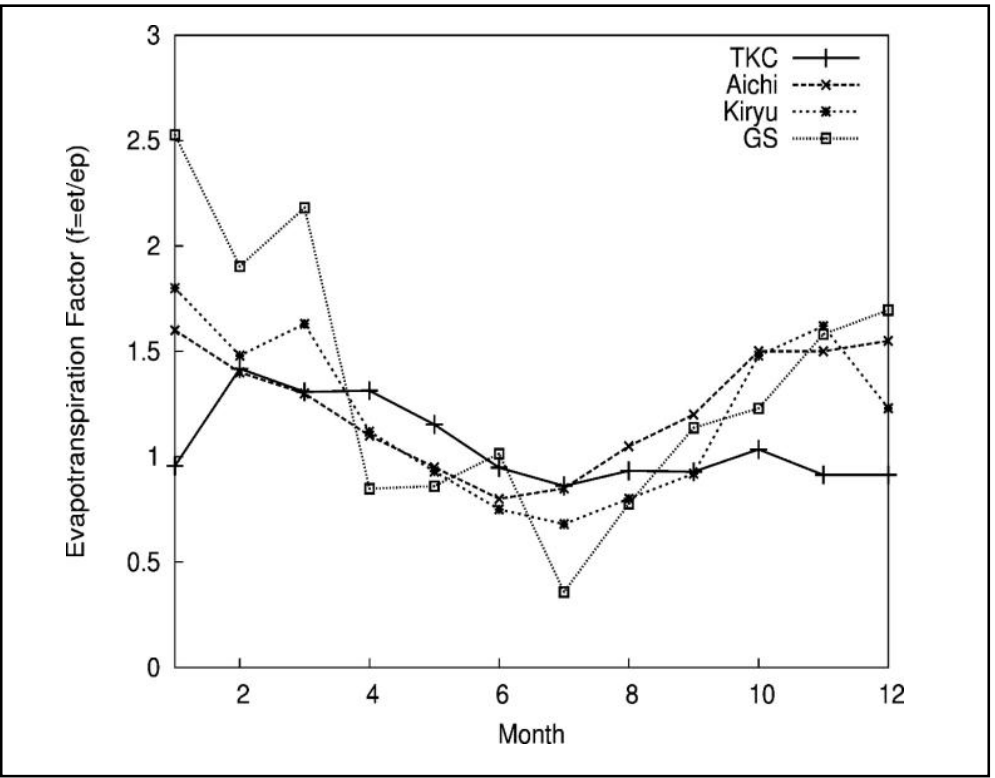

Figure 2. Monthly evapotranspiration factor, $f_{e p}$. 
The $f_{e p}$ estimated value from November to January on the TKC site was underestimate compared to other sites. Agreeing with Kosugi and Katsuyama (2007) presented decreased evapotranspiration in winter. On the other hand, the $f_{e p}$ of GS site from December to March seems to be overestimated. In general, winter PET shows no systematic underestimation but fails to reproduce the spatial variability of PET (Prudhomme \& Williamson, 2013), thus $f_{e p}$ for winter appears to be a poor correction factor for Hamon PET. In fact that TKC and GS site belongs to cool-temperate climatic zone, snow covers the forest floor and canopy from November to January (Saitoh, Tamagawa, Muraoka, \& Koizumi, 2011). The TKC and GS temperature declines around or below $0{ }^{\circ} \mathrm{C}$ and solar radiation is low during winter. Figure 3 indicated the monthly average and range of $f_{e p}$ at GS site are small during growing season. Otherwise, the range of fluctuation of monthly GS $f_{e p}$ is large in the winter season (December to March) over 23 years with the standard error of the mean (SEM) which were 0.84, 1.7, 0.9, and 2.6, respectively. During the winter there is little available sunshine time, less temperature, less leaf, and little plant growth. Moreover, the winter precipitations occur as snow or rain that contributed to fluctuations of monthly water balance.

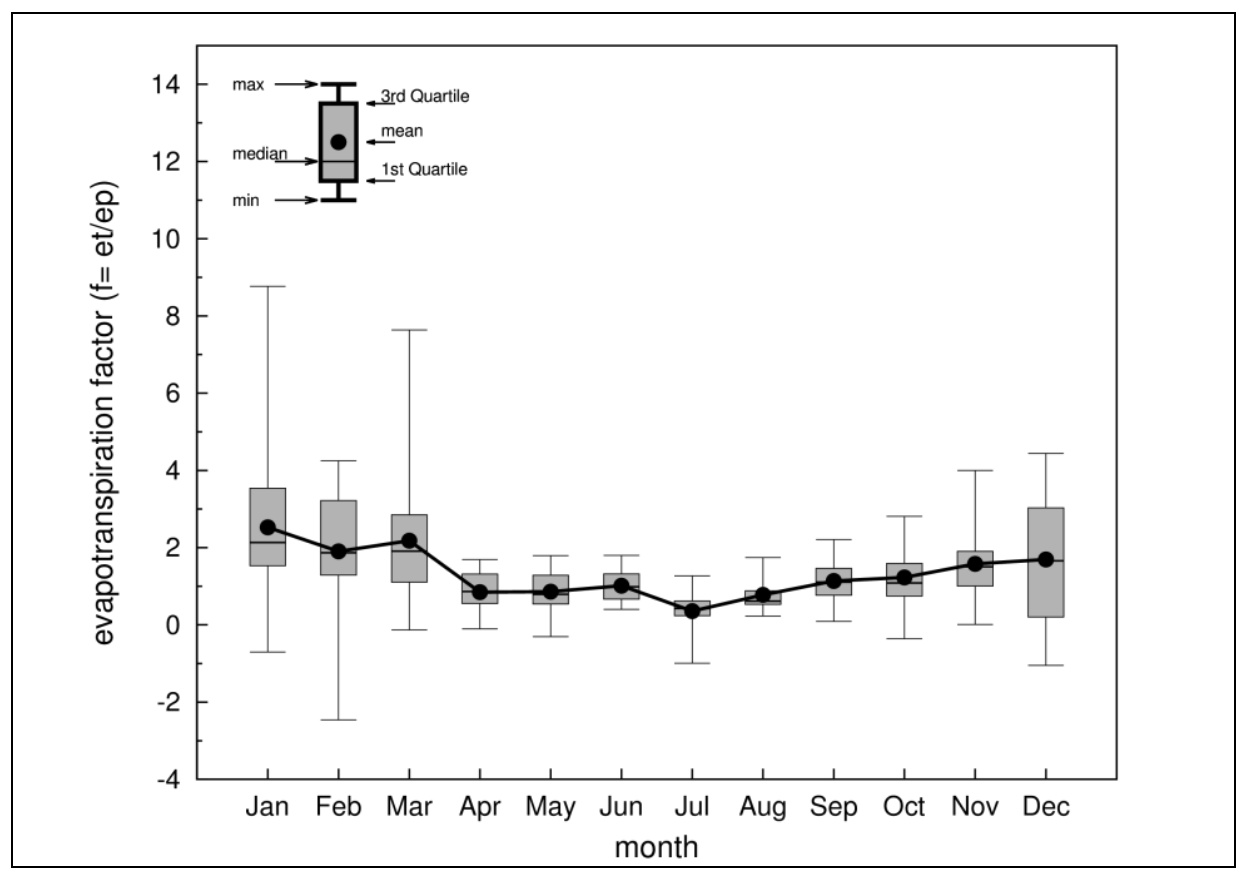

Figure 3. The monthly average and range of $f_{e p}$ over study periods.

In spite of that, Table 1, Figure 2, and Figure 3 show the variations of $f_{e p}$ both site are well corresponded for growing season. Kosugi and Katsuyama (2007) again presented the annual fluctuations in evapotranspiration which were small during growing season. Similar trend of seasonal changes was reported by Sawano, Hotta, Tanaka, and Tsuboyama (2015) where evapotranspiration suggested an applicable possibility to use $f_{e p}$ in growing season. In this study, the $f_{e p}$ was confirmed and validated to provide a good alternative for estimating the evapotranspiration rate when only daylight sunshine and temperature data are available (Hamon, 1960; Fisher, Whittaker, \& Malhi, 2011).

\section{Analysis of Long Term Variability of Water Balance}

The linear trend analysis was used to analyze long-term variations of the annual water balance in GS that is shown in Figure 4. Annual precipitation and runoff are summarized from observation daily rainfall and 
discharge data. By subtracting observed annual runoff from annual precipitation equation (5), annual loss that is assumed as actual evapotranspiration $\left(e_{t}\right)$ is obtained which values of all variables fluctuate over 23 years. Direct runoff is separated from the base flow by hydrograph separation (Hewlett, 1966). The extraction of linear trend of the water balance components: rainfall has a slightly changed trend, $R=-3.143$ (year) +8528 ; direct flow has a significant decreasing trend, $Q_{d}=-13.211$ (year) +27735 ; baseflow trend has a slightly changed trend, $Q_{b}=-1.454($ year $)+3048$; loss (AET, $e_{t}$ ) has a strong increasing trend, $e_{t}=11.52$ (year) -22225 ; and trend of PET, $e_{p}=0.267$ (year) +97 . This means that rainfall and baseflow tend to have small change by $-72 \mathrm{~mm}$ and $-33 \mathrm{~mm}$, respectively; direct flow decreases by $-304 \mathrm{~mm}$; loss $\left(e_{t}\right)$ increases by $265 \mathrm{~mm}$ over 23 years period.

Furthermore, the order of PET from Hamon expression and annual loss (AET) are approximately equal. This result found that the Hamon PET without correction factor has been underestimated AET (Xu \& Singh, 2001; Rao, Sun, Ford, \& Vose, 2011). In the previous study (Zainal, Ohashi, Sakurai, Kojima, \& Shinoda, 2012), the climate factor shows a weak trend in temperature, therefore the climate variability cannot explain in the increase in AET. The interpretation of the increasing trend is forest growth that is expected to cause the increase in evapotranspiration as well decrease in direct runoff.

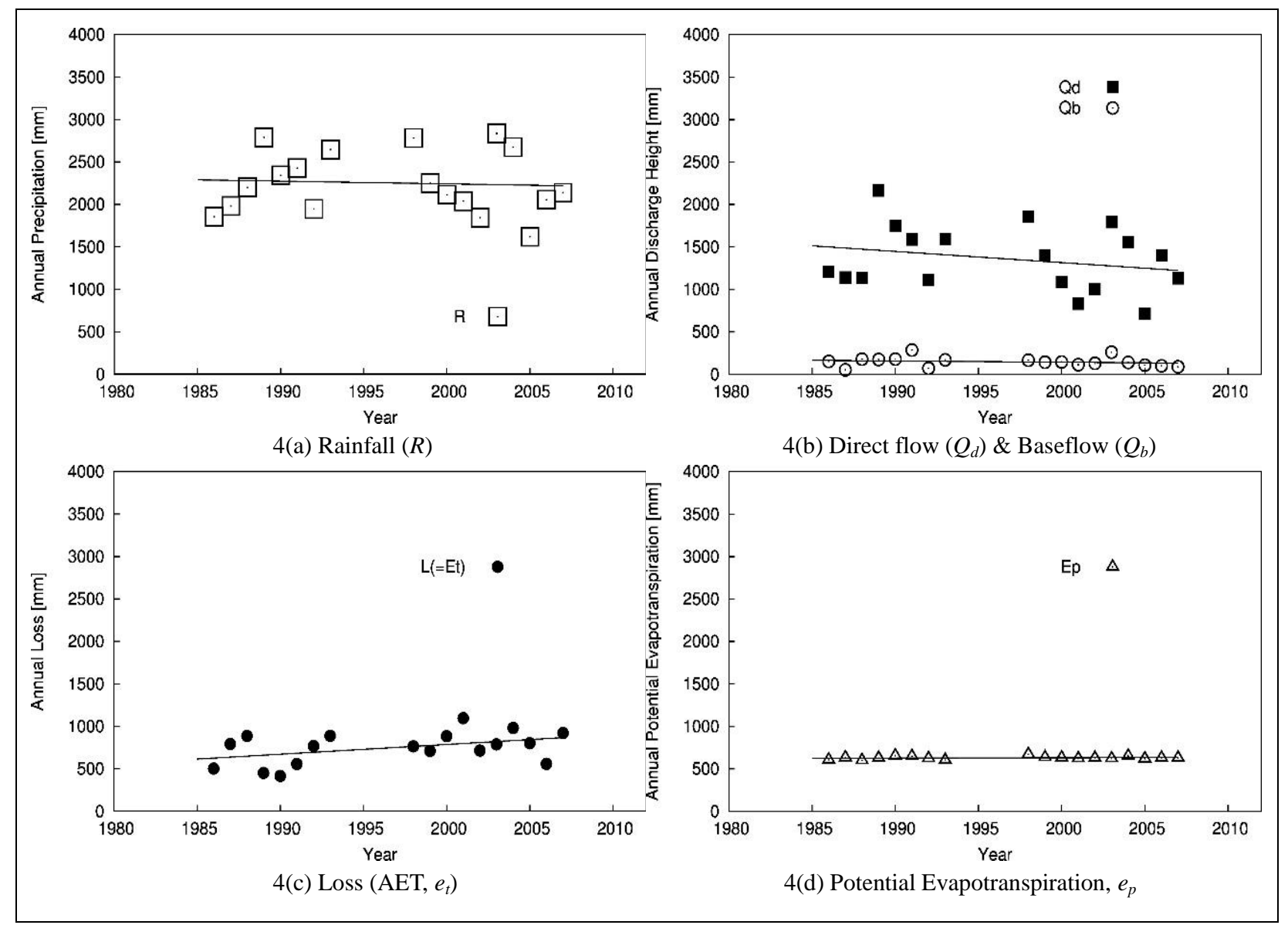

Figure 4. (a), (b), (c), (d) Long-term annual water balance.

\section{Correlation of $f_{e p}$ and NDVI Trend}

Kojima et al. (2013) have analyzed the long term Normalized Difference Vegetation Index (NDVI) in the study area by using the satellite image, which consists of the Landsat/MSS, Landsat/TM, and Terra/ASTER 
image. It was analyzed from 1984 to 2010 with atmospheric correction using 6S code (Second Simulation of the Satellite Signal in the Solar Spectrum). The observation of the vegetation has been carried out traditionally through NDVI, which is calculated using the radiometric information obtained for the red (R) and near-infrared $(N I R)$ wavelengths of the electromagnetic spectrum $(N D V I=((N I R)-R) /((N I R)+R))$; that respond to changes in the amount of green biomass (Jensen, 2007). The long term NDVI trend analysis performed on Figure 5 is that positive and significant values indicate an increase in the vegetation biomass, which occurred during the study period in the GS, GU, and MR forest catchment. The significant correlation coefficients (r) were 0.92 , 0.82, and 0.9 in each catchment, respectively. It was confirmed that forest growth is due to the forest management activities over the study area. It was checked that reproduction canopy on upper (GU) and middle catchment (MR) are growing (Zainal, Ohashi, Sakurai, Kojima, \& Shinoda, 2012; Kojima, Zainal, Oike, Ohashi, $\&$ Shinoda, 2013) and may not be well managed after plantation.

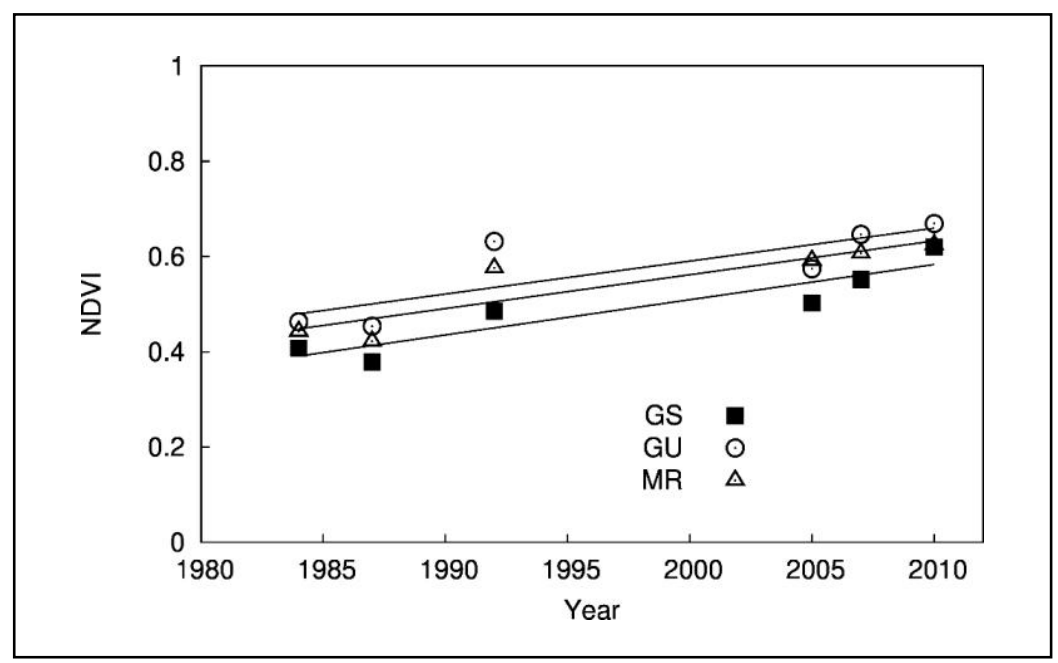

Figure 5. Long-term variations of NDVI.

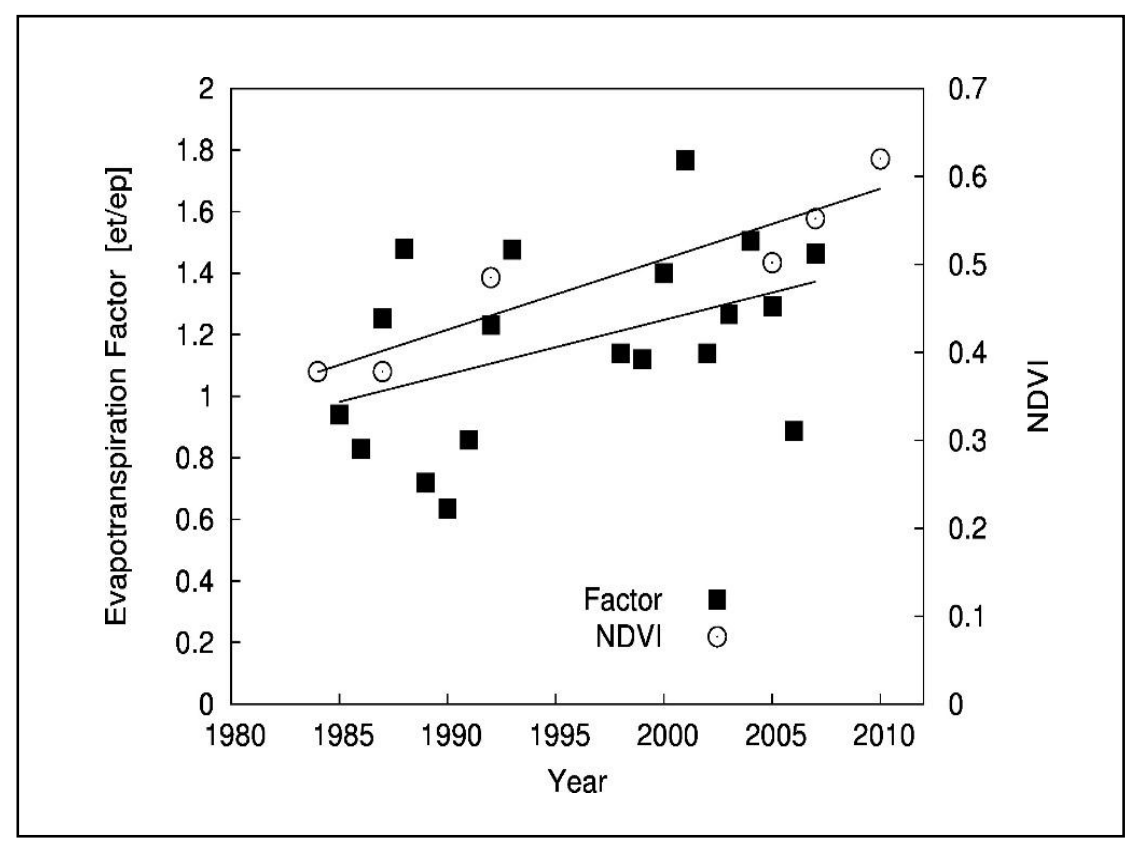

Figure 6. Long-term variations of $\left(e_{t} / e_{p}\right)$ and NDVI (GS). 
The $f_{e p}$ is used to adjust the Hamon PET to account for influence of the forest growth on the evapotranspiration process. Figure 6 shows the trends of NDVI and annual $f_{e p}$ variables look similar. This means both of the tree evapotranspiration and the light absorption increase roughly at the same rate in long-term annual estimation. Wang, Li, Cribb, and Sparrow (2007) argued that water loss $\left(e_{t}\right)$ and photosynthesis are linked. The relationship between long-term NDVI data and observed annual $f_{e p}$ for forest study area on Figure 7 was found linear, with the correlation coefficient $(r)$ is 0.55 and the proportion of variability $\left(r^{2}\right)$ is 0.30 . The developed correlation equations is given below:

$$
f_{e p}=1.40 \mathrm{NDVI}+0.488
$$

The simple equation (6) may help to monitor evapotranspiration rate in the growing season by using NDVI time series data and combining with Hamon PET estimation. Furthermore, developing relationship of $f_{e p}$ and NDVI could enhance the accuracy in estimating evapotranspiration factor values.

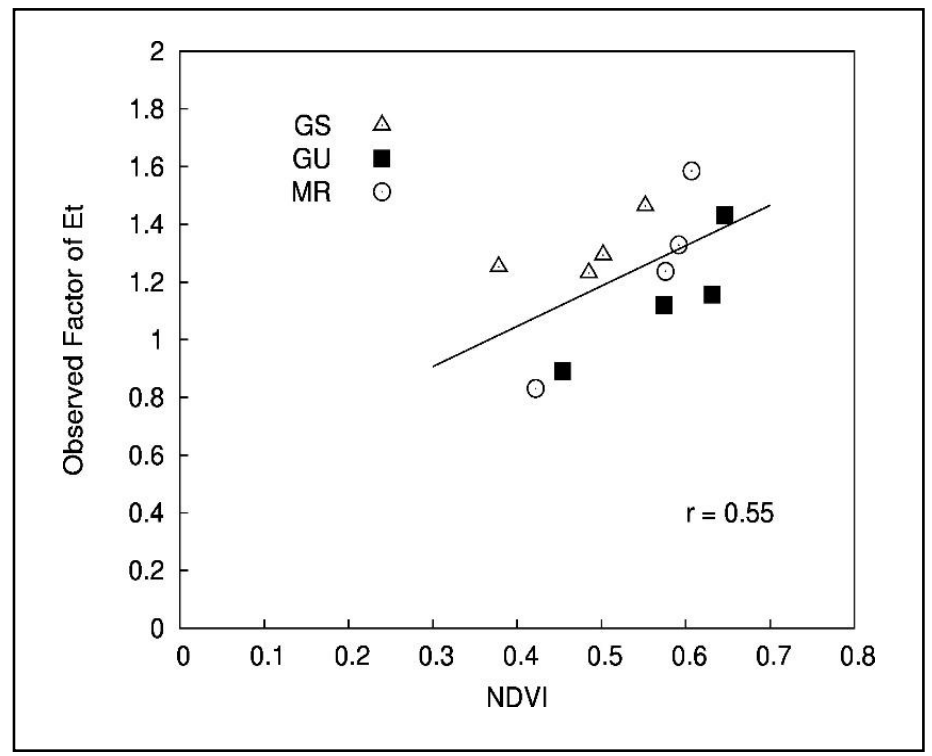

Figure 7. Relationship of $f_{e p}$ and NDVI.

\section{Conclusion}

Because of the complex evapotranspiration and the large number of model to estimate evapotranspiration with characteristic each area, then the long-term annual water balance equation is the simple method, when precipitation and runoff are known. Water balance analysis suggests that direct runoff decreases and actual evapotranspiration (AET) increase is mainly associated with forest growth. Due to increasing of forest cover, evapotranspiration losses in study site are more able to increase than potential evapotranspiration (PET). However, no significant change was found in the long-term annual precipitation.

The long-term annual PET estimated from the Hamon methods was correlated with the AET values derived from the water balances. Here, the long-term annual evapotranspiration factor of Hamon PET was tending to increase and monthly evapotranspiration factor was changed in every season. This study produces a useable monthly and annually evapotranspiration factor for Hamon PET during the growing season that can be used to estimate actual evapotranspiration where the region has less parameter input.

The simple linear regression model was developed to establish a general relationship between NDVI and the evapotranspiration factor from Hamon PET. The positive correlations were found between annual 
evapotranspiration factor and NDVI over vegetated area. In spite of fact that limited data availability, thus the precision of this model could be further improved by adding more hydrological and NDVI data. This model might be utilized as a reliable water resource monitoring and drought mitigation function. In the macro perspective, less direct runoff during rainfall and no change of base flow amount over the long term in rain forest is a good forest watershed function. Although the models are not directly applicable to other regions, the concept of the models would be useful in developing similar models applicable to other regions. The result of this study is suggestion to further utilization of winter data in reliable modeling for annual water balance.

\section{References}

Alkaeed, O., Flores, C., Jinno, K., \& Tsutsumi, A. (2006). Comparison of several reference evapotranspiration methods for Itoshima Peninsula area, Fukuoka, Japan. Memoirs of the Faculty of Engineering, Kyushu University, 66, 1.

Arakaki, T., Shimizu, A., Kobeya, N., Ikuzawa, H., Shimizu, T., Iida, S., \& Furugen, H. (2014). Calculation of forest potential evapotranspiration of Okinawa in Japan using the Penman equation. Journal of Water Resource and Protection, 6, 813-820.

Biao, Z., Wenhua, L., Gaodi, X., \& Yu, X. (2010). Water conservation of forest ecosystem in Beijing and its value. Ecological Economics, 69, 1416-1426.

Brutsaert, W. (2005). Hydrology-An introduction. Cambridge University Press.

Calder, I. R. (2007). Forest and water-ensuring forest benefits outweigh water costs. Forest Ecology and Management, 251, $110-120$.

Chisholm, R. A., Muller-Landau, H. C., Rahman, K. A., Bebber D. P., Bin, Y., Bohlman, S. A., \& Zimmerman, J. K. (2013). Scale-dependent relationships between tree species richness and ecosystem functions in forests. Journal of Ecosystem, 101, 1214-1224.

Creed, I. F., Sass, G. Z., Buttle, J. M., \& Jones J. A. (2011). Hydrological principles for sustainable management of forest ecosystems. Hydrological Processes.

Elkin, C., Giuggiola, A., Rigling, A., \& Bugmann, H. (2015). Short-long-term efficacy of forest thinning to mitigate drought impacts in mountain forests in the European Alps. Ecological Society of America, 25, 1083-1098.

Egami, Y., Hayashi, S., Kawabe, H., Honda, K., \& Shimaji, I. (1995). A decreasing tendency of evapotranspiration in summer of the scanty-year'87. Journal of Japanese Forestry Society, 77, 4.

Fisher, J. B., Whittaker, R. J., \& Malhi, Y. (2011). Potential evapotranspiration in geographical ecology. Global Ecology and Biogeography, 20, 1-18.

Gifu, P. (2004). Report of integrated model work of reinforcing water and soil conserving function (The Kiso region).

Hamon, W. R. (1960). Estimating potential evapotranspiration.

Hewlett, J. D., \& Hibbert, A. R. (1966). Factors affecting the response of small watersheds to precipitations in humid areas. Oxford \& N.Y.: Pergamon Press.

Ishii, M. A. (1989). A long-term runoff model for the drainage basin of a mountain district and the seasonal variation of the coefficient of evapotranspiration by the Hamon formula. Journal of the Japanese Forestry Society, 3, 99-107.

Japan Meteorological Agency (JMA). http://www.jma.go.jp/

Jensen, \& John, R. (2007). Remote sensing of the environment an earth resource perspective. NJ: Prentice Hall Series in Geographic Information Science.

Jianbio, L., Ge, S., Steven, G. M., \& Devendra, A. (2005). A comparison of six potential evapotranspiration methods for regional use in the Southeastern UNITED STATES. Journal of the American Water Resources Association (JAWRA), 41, 621-633.

Johnson, L. F., \& Trout, T. J. (2012). Satellite NDVI assisted monitoring of vegetable crop evapotranspiration in California's San Joaquin Valley. Remote Sensing, 4, 439-455.

Kamble, B., Irmak, A., \& Hubbard, K. (2013). Estimating crop coefficients using remote sensing-based vegetation index. Remote Sensing, 5, 1588-1602.

Kojima, T., Zainal, E., Oike, H., Ohashi, K., \& Shinoda, S. (2013). Evaluation of green dam in a forested small catchment with long-term hydrological data and tank model. Journal of Japan Society of Civil Engineers, 69, 137-144 (in Japanese with English summary).

Komatsu, H., Maita, E., \& Otsuki, K. (2008). A model to estimate annual forest evapotranspiration in Japan from mean annual temperature. Journal of Hydrology, 348, 330-340. 
Kosugi, Y., \& Katsuyama, M. (2007). Evapotranspiration over Japanese cypress forest. II. Comparison of the eddy covariance and water budget methods. Journal of Hydrology, 334, 305-311.

Makino, S., Goto, H., Inoue, T., Sueyoshi, M., Okabe, K., Hasegawa, M., \& Okochi, I. (2006). The monitoring of insects to maintain biodiversity in Ogawa forest reserve. Environmental Monitoring and Assessment, 120, 477-485.

MAFF-Ministry of Agriculture, Forestry and Fisheries. (2013). Annual report on forest and forestry in Japan fiscal year 2013.

Miura, S., Amacher, M., Hofer, T., Ayanz, J., Ernawati, \& Thackway, R. (2015). Protective functions and ecosystem services of global forests in the past quarter-century. Forest Ecology and Management, 352, 35-46.

Murakami, S., Tsuboyama, Y., Shimizu, T., Fujieda, M., \& Noguchi, S. (2000). Variation of evapotranspiration with stand age and climate in a small Japanese forested catchment. Journal of Hydrology, 227, 114-127.

Oudin, L., Hervieu, F., Michel, C., \& Loumagne, C. (2005). Which potential evapotranspiration input for a lumped rainfall-runoff model? Part 2-towards a simple and efficient potential evapotranspiration model for rainfall-runoff modeling. Journal of Hydrology, 303, 209-306.

Prudhomme, C., \& Williamson, J. (2013). Derivation of RCM-driven potential evapotranspiration for hydrological climate change impact analysis in Great Britain: A comparison of methods and associated uncertainty in future projections. Hydrology and Earth System Science (HESS), 17, 1365-1377.

Rao, L. Y., Sun, G., Ford, C. R., \& Vose, J. M. (2011). Modeling potential evapotranspiration of two forested watersheds in the southern Appalachians. American Society of Agriculture and Biological Engineers (ASABE), 54(6), 2067-2078.

Razafindrable, B. H., He, B., Inoue, S., Ezaki, T., \& Shaw, R. (2010). The role of forest stand density in controlling soil erosion: Implications to sediment related disasters in Japan. Environmental Monitoring and Assessment, 160, 337-354.

Ryu, J., Jang, W. S., Kim, J., Choi, J. D., Engel, B. A., Yang, J. E., \& Lim, K. J. (2016). Development of a watershed-scale long-term hydrologic impact assessment model with the asymptotic curve number regression equation. Water, 8, 153.

Sach, F., Svihla, V., Cernohous, V., \& Kantor, P. (2014). Management of mountain forests in the hydrology of landscape, the Czech Republic. Journal of Forest Science, 60, 42-50.

Saitoh, T. M., Tamagawa, I., Muraoka, H., \& Koizumi, H. (2011). Energy balance closure over a cool temperate forest in steeply sloping topography during snowfall and snow-free periods. Agriculture Meteorology, 67, 107-116.

Sato, Y., Kojiri, T., Michihiro, Y., Suzuki, Y., \& Nakakita, E. (2013). Assessment of climate change impacts on river discharge in Japan using the super-high-resolution MRI-AGCM. Hydrological Processes, 9828.

Sawai, N., Takara, K., \& Kobayashi, K. (2013). Evaluation of water retention capacity and flood control function of the forest catchment. Journal on Food, Agriculture and Society, 1.

Sawano, S., Hotta, N., Tanaka, N., \& Tsuboyama, Y. (2015). Development of a simple forest evapotranspiration model using a process-oriented model as a reference to parameterize data from a wide range of environmental conditions. Ecological Modelling, 309, 93-109.

Senay, G. B., Leake, S., Nagler, P. L., Artan, G., Dickinson, J., Cordova, J. T., \& Glenn, E. P. (2011). Estimating basin scale evapotranspiration (ET) by water balance and remote sensing methods. Hydrological Process, 25, 4037-4049.

Shimizu, A., Shimizu, T., Miyabuchi, Y., \& Ogawa, Y. (2003). Evapotranspiration and runoff in a forest watershed, western Japan. Hydrological Processes, 17, 3125-3139.

Sun, G., McNulty, S. G., Myers, J. A. M., \& Cohen, E. C. (2008). Impacts of multiple stresses on water demand and supply across the Southeastern United States. Journal of American Water Resources Association (JAWRA), 44, 1441-1457.

Suzuki, R., \& Masuda, K. (2004). Interannual covariability found in evapotranspiration and satellite-derived vegetation indices over Northern Asia. Journal of the Meteorological Society of Japan, 82, 1233-1241.

Tetens, V. O. (1930). Uber einige meteorologische. Begriffe, Zeitschrift fur Geophysik, 6, 297-309.

Tsukamoto, Y. (1992). Forest hydrology. Bun-eido Publishing Co., Ltd. (Book in Japanese).

Wang, K., Wang, P., Li, Z., Cribb, M., \& Sparrow, M. (2007). A simple method to estimate actual evapotranspiration from a combination of net radiation, vegetation index, and temperature. Journal of Geophysical Research, 112, D15.

Ward, A. D., \& Trimble, S. W. (2004). Environmental hydrology. Lewis Publishers.

Watanabe, Y., Konishi, S., Ishihara, K., \& Tezuka, T. (2011). Evaluation of carbon dioxide absorption by forest in Japan. Zero-Carbon Energy Kyoto 2010, Green Energy and Technology, 25-31.

Westerhoff, R. S. (2015). Using uncertainty of Penman and Penman-Monteith methods in combined satellite and ground-based evapotranspiration estimates. Remote Sensing of Environment, 169, 102-112.

Xu, C. Y., \& Singh, V. P. (2001). Evaluation and generalization of temperature-based methods for calculating evaporation. Hydrological Process, 15, 305-319. 
Yamane, M. (2003). Forest management and water resource conservation: Cost-sharing systems between upstream and downstream communities in Japan. People and Forest-Policy and Local Reality in Southeast Asia, the Russian Far East, and Japan, 3, 321-336. Institute for Global Environmental Strategies.

Zainal, E., Ohashi, K., Sakurai, M., Kojima, T., \& Shinoda, S. (2012). Long term variable properties of runoff process in a mountainous forested catchment. Advances in River Engineering, JSCE, 18, 741-746.

Zhang, L., Dawes, W. R., \& Walker, G. R. (2001). Response of mean annual evapotranspiration to vegetation changes at catchment scale. Water Resources Research, 37(3), 701-708.

Zhou, G., Sun, G., Wang, X., Zhou, C., McNulty, S. G., Vose, J. M., \& Amatya, D. M. (2008). Estimating forest ecosystem evapotranspiration at multiple temporal scales with a dimension analysis approach. Journal of American Water Resources Association (JAWRA), 44, 208-221. 